\title{
Kerk, volk en owerheid in die 1858-grondwet van die Zuid-Afrikaansche Republiek
}

\author{
W A Dreyer \& S J Botha \\ Universiteit van Pretoria
}

\begin{abstract}
Church, people and government in the 1858 constitution of the South African Republic

During the years 1855 to 1858 the South African Republic in the Transvaal created a new constitution. In this constitution a unique relationship between church, people and government was visible. This relationship was influenced by the Calvinist confessions of the sixteenth century, the theology of $W$ à Brakel and orthodox Calvinism, the federal concepts of the Old Testament and republican ideas of the Netherlands and Cape Patriots. It becomes clear that the history of the church in the Transvaal was directly influenced by the general history of the South African Republic.
\end{abstract}

\section{HISTORIESE AGTERGROND}

Die Voortrekker-era is formeel afgesluit met die Sandrivier Konvensie (17 Januarie 1852), toe Groot Brittanje die gebied noord van die Vaalrivier as soewereine staat erken het. Die Voortrekkers het daarmee hulle ideaal van politieke selfbeskikking en vryheid bereik. Die Transvaalse republiek is aanvanklik volgens die Drie-en-dertig Artikels regeer, maar aangesien dit onvoldoende was, het daar spoedig 'n behoefte aan 'n grondwet ontstaan. Die Volksraad het op 18 September 1855 'n kommissie aangewys om 'een ontwerp van wetten te maken' (S A Argiefstukke Tvl, no 3:104 art 68).

Die kommissie het bestaan uit S J P Kruger, H S Bosman, H S Lombardt, H B L Klopper, A P van der Walt, D H Botha, G J Kruger en J Stuart. Op 6 November 1855 het die kommissie die eerste konsepwetgewing met 327 artikels aan die Volksraad voorgelê. Hierdie konsep kwalifiseer tegnies gesproke nie as 'n grondwet nie. Die

* Hierdie artikel is gebaseer op navorsingsresultate verkry in die doktorale proefskrif, ingedien en aanvaar as deel van die vereistes vir die DD-graad (1995), Departement Kerkgeskiedenis en Kerkreg, Fakulteit Teologie (Afd A), Universiteit van Pretoria, onder leiding van prof dr S J Botha. 
opskrif van die konsepwetgewing lui Nieuwe Wetten voor de Hollandsche Afrikanen benoorden de Vaal Rivier (S A Argiefstukke Tvl, no 3:381). Die konsep was 'n poging om basiese beginselsake uiteen te sit en was 'n groot verbetering op die Drieen-Dertig Artikels.

Die konsep van 1855 omskryf die kerk se voorregte en posisie in die ZuidAfrikaansche Republiek breedvoerig. Die volgende artikels raak die kerk direk:

Art 10: 'Het verlangt de uitbreiding van het Christendom onder de heidenen, doch onder bepaald voorzorgen tegen misleiding en bedrog'.

Art 12: 'Het behoudt uitsluitend aan zich de bescherming en verdediging van kerk en staat'.

Art 17: 'Het zal jaarlyks, van den volksraad, eene begrootingswet van algemeene uitgaven voor kerk en staat inwachten ....'

Art 23: 'Het volk wil zyne Nederduitsch Hervormde godsdienst, zoo als die in de jaren 1618 en 1619 door de synode te Dordrecht is vasgesteld, behouden'.

Art 24: 'Het verkiest in zyn midden geene Roomsche kerken toe te laten en ook geene ander Protestantsche dan de zoodanige, waarin dezelfde hoofdzom van Christelyk geloof geleerd wordt, als is opgegeven in de Heidelbergsche Catechismus'.

Art 25: 'Het zal geene andere vertegenwoordigers in den volksraad aanstellen, dan degenen die lidmaten der Nederduitsch Hervormde gemeente zyn'.

Art 26: 'Het erkent geen ander kerkelyk gezag dan dat, wat door kerkeraden zyner Ned. Hervormde gemeenten is of wordt goedgekeurd, aangenomen en vasgesteld'.

Art 27: 'Het wil zyne kerk niet minder ongeschonden bewaren, dan de onafhankelykheid van zynen staat'.

Art 29: 'Het volk verlangt de opbouw, bloei en welvaart van kerk en staat en uit dien hoofde, voorziening in de behoefte aan Ned. Hervormde predikanten en schoolonderwyzers'.

(SA Argiefstukke Tvl, no 3:382) 
Ook ander bepalings raak die verhouding tussen die kerk en die owerheid, onder andere dat die staatspresident 'n lidmaat van die Nederduitsch Hervormde Kerk moet wees (art 34) en dat die onderwysers direk onder toesig van die predikante staan (art 236). Daar is ook besluit dat die naam van die republiek die Zuid-Afrikaansche Republiek (ZAR) sal wees.

Omdat niemand van die Lydenburggroep op die kommissie gedien het nie, wou Lydenburg nie die konsep van 1855 erken of aanvaar nie. Dit het veroorsaak dat die Volksraad in November 1855 die konsep verwerp het. Daarop het ds Dirk Van der Hoff bedank as predikant, en as rede het hy die wetteloosheid van die land aangegee. So het hy 'kerklike' druk uitgeoefen om die wette aanvaar te kry. Die Volksraad het hom ingeroep en hom beboet met 100 riksdaalders, waarop Van der Hoff sy bedanking teruggetrek het (S A Argiefstukke Tvl, no 3:109). Die Volksraad het toe besluit om die wette voorlopig goed te keur, met dien verstande dat die publiek eers geleentheid sou kry om kommentaar te lewer.

$\mathrm{Na}$ hierdie besluite het generaals $\mathrm{M}$ W Pretorius en T F Dreyer deur die ZuidAfrikaansche Republiek gereis om die wette, asook die nie-inlywing van die Transvaalse gemeentes by die Kaapse Sinode, met die publiek te bespreek. Die uiteinde van hierdie vergaderings was dat daar besluit is om 'n volkskongres op 16 Desember 1856 te hou waar die wette gefinaliseer sou word. Elke veldkornetskap het een verteenwoordiger na die volkskongres gestuur. Die 24 persone het op Potchefstroom byeen gekom en nadat die nodige veranderinge aangebring is, is die konsep op 5 Januarie 1857 bekragtig. Hierdie 1857 weergawe van die konsep verskil, wat die verhouding tussen kerk en owerheid betref, alleen in die numerering. Die 1855 voorstelle is egter net so behou. Die bekende Vierkleur is ook by hierdie kongres aanvaar as die vlag van die Zuid-Afrikaansche Republiek. Die vlag is deur dominee Van der Hoff en sy broer ontwerp (Engelbrecht 1953:127). Die kongres het ook vir Pretorius as staatspresident aangewys. Pretorius is die volgende dag deur Van der Hoff in die Hervormde kerkgebou te Potchefstroom as president ingesweer en die Vierkleur is vir die eerste keer gehys.

\section{DIE ROL VAN DIE NEDERDUITSCH HERVORMDE KERK IN DIE STAATKUNDIGE GEBEURE}

Ds Van der Hoff en die Algemene Kerkvergadering was ten nouste by die staatkundige gebeure betrokke. Van der Hoff het hom beywer vir die staatkundige ontwikkeling en bestendiging van die jong republiek. Hy het nie net die amptelike plegtighede waargeneem deur die president en al die volksraadslede in te sweer nie maar, soos reeds gemeld, het hy ook die vlag (Vierkleur) ontwerp en 'n vlaglied gekomponeer. 
Hy het by verskillende geleenthede toesprake gehou om die betrokke saak te bevorder. So het hy sy invloed as predikant gebruik om die lidmate van die kerk tot eensgesindheid en die aanvaarding van die nuwe wette aan te moedig. Soos reeds gemeld, het hy selfs as predikant bedank om dit te bereik.

Die nuwe grondwet is ook aan die Sesde Algemene Kerkvergadering (A K V), wat op 24 Februarie 1857 spesiaal vir die doel te Pretoria vergader het, voorgelê (Notule A K V 1857:22). Dit is belangrik om daarop te let dat die Algemene Kerkvergadering hierdie landswette bekragtig en onderteken het, wat insigself 'n buitengewone wyse van handeling was. Hierin word die unieke en noue verbintenis tussen kerk, volk en owerheid in die Zuid-Afrikaansche Republiek duidelik sigbaar. Die Algemene Kerkvergadering het eenparig die nuwe wette goedgekeur en onderteken.

Die Algemene Kerkvergadering besluit ook op hierdie vergadering, na 'n voorstel van ouderling A Grobler, om 'n brief aan die 'verschillende hoofden dezer Republiek' te skryf, om hulle aan te spoor tot versoening ( $\mathrm{R}$ 1355/57). Die brief het by sommige leiers uitgekom, onder andere by kommandant-generaal S Schoeman en W F Joubert. Die Algemene Kerkvergadering het hom hierdeur op die staatkundige terrein begeef, want in die brief word gestel:

Ofschoon het niet in onze roeping ligt en ook niet tot onze werkkring behoort, om ons eenigzins in te laten met de politiek, zoo rekenen wij het toch van onzen plicht, om met $U$ over den tegenwoordigen toestand van zaken te spreken. Wij zien de ongelukkige verdeeldheid, die er bestaat in politieke aangelegenheden, en wij huiveren voor het gevolgen, die daaruit zullen kunnen voortvloeien - daarom verzoeken wij u, om onderling eene bijeenkomst te houden ... ten einde onder Gods zegen broederlijk met elkander te verenigen, en den band van eenheid, vrede en liefde onder ons te herstellen.

(in Engelbrecht 1953:129)

Die Algemene Kerkvergadering bied dan ook aan dat 'n kommissie, insluitende ds Van der Hoff, teenwoordig sou kon wees by die byeenkoms om die Volksraad van raad te bedien. Die Algemene Kerkvergadering wou duidelik aan die een kant die onderskeid tussen kerk en owerheid handhaaf en nie op die politieke terrein oortree nie, maar aan die ander kant wou die Algemene Kerkvergadering teenoor die owerheid getuig en die volk oproep tot eensgesindheid. Die Algemene Kerkvergadering wou selfs die rol van politieke bemiddelaar speel in die plofbare situasie. 
Aanvanklik het hierdie skrywe weinig uitwerking gehad, aangesien die mense van Zoutpansberg, onder leiding van S Schoeman, nie die grondwet wou aanvaar nie. Hulle het probleme gehad met die feit dat daar 'n staatspresident sou wees wat volgens hulle oorheersing deur ' $n$ enkeling in die hand sou werk. Uiteindelik het die Zoutpan bergers die grondwet aanvaar, maar eers na die kerk se ingrype en nadat Schoeman die pos van kommandant-generaal aangebied is en hy dit aanvaar het. Die Vierkleur is op 15 Maart 1858 ook in die Zoutpansberge gehys, nadat die finale grondwet in die staatskoerant gepubliseer is.

Ten slotte miskien 'n paar opmerkings oor die persoon van ds Van der Hoff: Dit is baie duidelik dat ds Van der Hoff hom gou reeds na sy aankoms in Transvaal volkome vereenselwig het met die aspirasies van die Afrikaner. Nie net gebruik hy sy invloed om die politieke aangeleenthede positief te beïnvloed nie, maar ons sien dit ook in sy vlaglied:

\author{
Vivat de vlag! Vivat de vlag! \\ Door vrijheid hier geplant! \\ Waai rond door Zuid'lik Afrika \\ Van Oost- tot Westerstrand. \\ Waai onbezoedeld; schoon en rein, \\ En wapper ook op zee; \\ Vertoon u aan de volk'ren oog \\ Tot aan de verste ree. \\ God zij met $\mathrm{u}$ - God zij met $\mathrm{u}$, \\ Gij maagdelijke vlag, \\ En met het volk, dat u verkoos, \\ Tot aan de jongste dag!
}

(in Engelbrecht 1953:128)

As 'n mens hierdie vlaglied interpreteer, word dit duidelik dat ds, Van der Hoff iets van die vryheidsdrang van die Afrikaners in die Transvaal verstaan het en waarskynlik self daarmee besiel was. Verder is dit duidelik uit die bede dat God met die vlag en met die volk moet wees, dat die verbondsverhouding tussen God en die volk (wat ook lidmate van die kerk is), hier meespreek. Dit is dieselfde gedagte wat ook in die Gelofte van 1838 by Bloedrivier uitgespreek is. Hier is nie sprake van 'n skeiding tussen geloof en politiek nie: die God van die kerk, is ook die God wat beskik oor die lotgevalle van volke en nasies en wat owerhede as instrument gebruik. Daarom is dit 
moontlik om binne die raamwerk van hierdie Calvinistiese denke ook in 'n vlaglied te mag bid dat God met die vlag en die volk sal wees. Dit is, interessant genoeg, ook die gedagte wat in Die Stem na vore kom.

\section{3. 'N ONTLEDING VAN DENKE WAT DIE 1858-GRONDWET VAN DIE ZUID-AFRIKAANSCHE REPUBLIEK BEPAAL HET}

\subsection{Politieke denke}

Dit is duidelik dat die Transvaalse 'Afrikanen' oortuigde republikeine was. Die heel eerste artikel van die grondwet stel dit duidelik dat die regeringsvorm van deze maatschappij zal zyn Republikeinsch. Hand aan hand met die republikeinse ideaal, loop die strewe na staatkundige vryheid wat in verskeie artikels aan die orde kom. Vir die Afrikaner in die Transvaal was selfbeskikking en politieke vryheid die hoogste ideaal. Dit blyk uit die feit dat van die artikels dikwels met die woorde 'het volk wil' begin. Die volk, en nie die individu nie, vorm die kern van die Transvaalse Afrikaners se politieke denke, want die volk is volgens hulle soewerein en die hoogste gesag. Daarom het hulle belangrike kwessies gereeld na volksvergaderings verwys met die oog op besluitneming (Niewoudt 1979:31). Daar was toe nog nie politieke partye wat namens die volk geregeer het nie. Die volk het direk deur middel van hulle verteenwoordigers en die volksvergaderings geregeer. Dit was dus 'n ware demokrasie of volksregering (Kleynhans 1966:117).

In die grondwet van die Zuid-Afrikaansche Republiek word die tipiese terminologie van die Patriotte-beweging teruggevind (vir 'n bespreking van die Patriottebeweging in Suid-Afrika vgl Beyers 1967). Die Bataafse grondwet van 1798 is 'n produk van Patriot-denke. As die grondwette van die Bataafse Republiek en ZuidAfrikaansche Republiek met mekaar vergelyk word, is daar duidelike ooreenkomste: die volksoewereiniteit vorm die sentrale beginsel in beide grondwette en frases soos Het volk verkiest/verklaart/wil word algemeen in beide gebruik. Hierdie uitdrukkings het almal te make het met die volk se wil (Wypkema 1939:334). Wypkema wys egter daarop dat die volkswil, soos uitgedruk in die Transvaalse grondwet van 1858, 'n stewiger basis het as in die Bataafse grondwet, omdat daar in die Transvaal nie politieke partye was wat as tussenganger tussen die volk en die owerheid opgetree het nie. In die Zuid Afrikaansche Republiek het daar deur middel van die volksvergaderings, kongresse en memories 'n direkte inspraak van die volk ten opsigte van wetgewing bestaan.

Die 1858-grondwet is ook deur die grondwet van die Verenigde State van Amerika (V S A) beïnvloed (Du Plessis 1968:815). Hierdie grondwet is in 1791 aanvaar, en J Stuart verwys daarna as ' $n$ voorbeeld. Die Patriotte in Nederland het ook baie hoë waardering vir die Amerikaanse vryheidstryd en grondwet gehad. Een van die leiers 
van die Patriotte in Nederland, Van der Capellen tot den Pol, het gereeld in sy geskrifte vir die Amerikaners in die bresse getree. Dit was ook op sy advies dat die Bataafse owerheid die kant van die Amerikaners teen die Engelse gekies het. Die grondwet van die Verenigde State van Amerika is ook so as voorbeeld gebruik met die opstel van die Bataafse grondwet. Die verskil is egter dat in die grondwet van die Verenigde State van Amerika die outonome mens die sentrale plek inneem, terwyl in die Bataafse en Zuid-Afikaansche Republiek se grondwette die soewereine volk die sentrale plek inneem.

Sonder om te veel te maak van die invloed van die Patriot-denke, is dit tog duidelik dat die Transvaalse Afrikaners in hulle politieke denke deur die Patriotte beinnloed is. Daarom gebruik hulle voortdurend terme soos republiek, volk, volkswil, volksoewereiniteit, vryheid en andere.

\subsection{Calvinisties-teokratiese denke}

Daar is ook verskille tussen die Bataafse en Zuid-Afrikaansche Republiek grondwette. Die grondwet van die Zuid-Afrikaansche Republiek vertoon byvoorbeeld duidelik Calvinisties-teokratiese tendense; iets wat nie in die Bataafse grondwet voorkom nie. Daar is die rol van die kerk juis geminimaliseer, veral nadat Ploos van Amstel in 1796 in die Bataafse parlement ' $n$ groter skeiding tussen kerk en staat voorgestel het en dit so aanvaar is (De Visser 1926:16; Murray 1962:75). Die grondwet van 1858 maak geen voorsiening vir die skeiding van kerk en staat nie. Inteendeel, die finale grondwet van 1858 is op 5 Maart 1858 in die staatskoerant gepubliseer onder die titel Grondwet van de Zuid-Afrikaansche Republiek (S A Argiefstukke Tvl, no 3:496) waarin Artikel 20 bepaal: 'en de Nederduitsch-Hervormde kerk zal de kerk van de Staat zyn' (S A Argiefstukke Tvl, no 3:498). Daarmee word die Nederduitsch Hervormde Kerk in effek as staatskerk, en daarmee ook as bevoorregte kerk, erken. Hierdie wet is deur die kommissieraad van die Volksraad, wat op 2 Februarie 1858 te Rustenburg vergader het, voorberei. In die notule van die kommissieraadsvergadering word uitdruklik gepraat van die staatskerk. In Artikel 13 van die notule word besluit om die 'Hoofdkerk of Staatskerk nog in aanmerking te nemen' (S A Argiefstukke Tvl, no 3:158).

Pont wys verder daarop dat die Bataafse volkswil, onder invloed van die Franse politieke filosofie, meer individualisties georiënteerd was, terwyl die indiwidu in die Transvaalse volkswil byna geen rol gespeel het nie. Die Transvaalse opvatting van die volk is meer Calvinisties bepaald, naamlik as 'n verbondsvolk van gedooptes. Hierdie verbondsvolk word saamgestel deur families, eerder as individue (Pont 1986:62). D W Kruger het byvoorbeeld daarop gewys dat president S J P Kruger die 'volk' as sy eie mense (die Afrikaners in Transvaal) beskou het; mense wat 'God se volk is', omdat 
hulle nie net Afrikaners was nie, maar ook lidmate van die kerk. Dit was verbondskinders oor wie hy, soos ' $n$ Moses, moes regeer en waak. Die vryheid en onafhanklikheid van hierdie volk moes soos 'n kleinnood bewaar word, want dit is uit die hand van God ontvang (Kruger 1963 II:86). As in aanmerking geneem word dat S J P Kruger deel van die kommissie was wat die Transvaalse grondwet opgestel het, kan dit wees dat die 'volk' waarvan in die grondwet gepraat word, nie net die volk van die Patriotdenke is nie, maar veral die verbondsvolk van die Calvinisties-teokratiese denke. Hier moet net omskryf word wat bedoel word met Calvinisties. Die Voortrekkers en die vroeë Transvaalse pioniers het nie Calvyn se eie werke geken, gelees of beskikbaar gehad nie (Brown 1990:533-554; Van Zijl 1992). Buitendien was Calvyn in die agtiende eeu en in die vroeë negentiende eeu, selfs in Nederland, 'n vergete figuur. Daar moet dus duidelik onderskei word tussen die denke van Calvyn en die Calvinisme. Die Calvinisme het dikwels dinge gesê wat gladnie in Calvyn se denke ingepas nie. Die wesenlike verskil tussen Calvyn en die Calvinisme is dat Calvyn konsekwent net wou sê wat die Skrif sê, terwyl veral die ortodokse Calvinisme in 'n sisteemdenke verval het. Die Calvinisme wat die Voortrekkers en Transvaalse pioniers beïnvloed het, was die Nadere Reformasie.

Van Zijl se navorsing het aangetoon dat die Voortrekkers oor die algemeen boeke uit die Nadere Reformasie gelees het (Van Zijl 1992). Veral die Redelijke Godsdienst van W à Brakel (à Brakel 1736) was bekend en het groot invloed uitgeoefen. Dit blyk onder andere uit 'n opmerking in die notule van die Sewende Algemene Kerkvergadering dat die kerkwet voorlopig in werking gestel moet word, en dat daar 'n byvoegsel moet kom wat die verhouding tussen kerk en owerheid sou omskryf 'en wel volgens't geen men daarvan vind in W à Brakel' (Notule A K V 1857:26). à Brakel se denke oor die verhouding tussen kerk en owerheid, die rol van die kerk in die politiek en die aflê van geloftes het ' $n$ groot invloed op die ou Transvaalse pioniers gehad. Dit 'het gevolglik ook die 1858-grondwet beïnvloed. Onder invloed van à Brakel is die beginsel van 'n teokratiese gemenebes in die Zuid-Afrikaansche Republiek aanvaar. Daarom wou die Transvalers 'n teokraties-Christelike gemenebes oprig, maar dan as 'n republiek. So vind daar in die grondwet van die Zuid-Afrikaansche Republiek 'n unieke vermenging van Calvinisties-teokratiese en Patriot-republikeinse denke plaas - met eersgenoemde die dominante.

Die Calvinisties-teokratiese denke word selfs nog meer sigbaar as daar gekyk word na die uitleg van die grondwet wat in die notule van die Kommissie van die Algemene Kerkvergadering te vinde is (Notule Kommissie van die Algemene Kerkvergadering, Aug 1862:97). Die Algemene Kerkvergadering het in September 1861 'n uitleg van Artikels 8, 9, 11, 20, 21, 22 en 23 van die regering gevra. Op 2 Augustus 1862 het die fungerende staatspresident en 'n afvaardiging van die Volksraad die Kommissie van die Algemene Kerkvergadering ontmoet en die artikels uitgelê. 
Die Algemene Kerkvergadering wou in die eerste plek weet wat bedoel word as daar in Artikel 8 gesê word, dat 'Het volk eischt ... het behoud van zyn Godsdienstig Geloof'. Die antwoord wat gegee is, was dat 'Godsdienstig Geloof' Nederduitsch Hervormde Kerk beteken het. Dit word duidelik uit hierdie uitleg dat die Nederduitsch Hervormde Kerk nie net staatskerk van die Zuid-Afrikaansche Republiek sou wees nie, maar ook die bevoorregte kerk wou word wat beskerm moes word, soos wat Artikel 36 in die Nederlandse Geloofsbelydenis van 'n owerheid verwag. Hier is dus geen sprake van 'n skeiding tussen kerk en staat nie, maar slegs van 'n onderskeid wat getref word (Engelbrecht 1953:135). Die bevoorregting van die Hervormde Kerk het onder andere beteken dat die predikante se traktement uit die staatskas betaal sou word, dat die owerheid sou help met die oprigting van kerkgeboue, dat hulle die predikante se pensioen sou waarborg en dat alleen lidmate van die Hervormde Kerk in die Volksraad en in die staatsdiens toegelaat sou word. Hieroor sê Pont:

So is die kerk, hoewel staatskerk, nié 'n kerk-van-die-staat nie, maar kerk-in-die-gemeenskap ten behoewe van die volk wat die staatsgesag in sy hande hou. In die teokratiese Christelike gemenebes word die kerk omskryf as 'n eiesoortige grootheid wat, omdat dit dan nog die hele burgery omvat, ook deur die burgery ondersteun en in stand gehou sal word.

(Pont 1991:792)

Die kerk het dus nie in die Zuid-Afrikaansche Republiek tot 'n staatsdepartement verword soos dit in die Skandinawiese lande met die Lutherse kerk gebeur het, en soos dit selfs op 'n stadium in Nederland en ook in die Kaap die situasie was nie. Die Calvinisitiese gedagte dat daar ' $n$ onderskeid tussen die kerk en die owerheid moet bly bestaan en dat elkeen sy eie bevoegdhede het, word hier gehandhaaf. As daar van die Hervormde Kerk as staatskerk gepraat word, is dit dus nie in sy verworde vorm nie. Die bedoeling was dat die owerheid die kerk in die lig van Artikel 36 in die Nederlandse Geloofsbelydenis wou bevorder en beskerm. Daarom laat die grondwet geen Rooms-Katolieke kerk in die Zuid-Afrikaansche Republiek toe nie - dit sou strydig wees met bogenoemde. Daar moet dus eerder aan die Hervormde Kerk as staatskerk gedink word in terme van 'n volkskerk, veral as in aanmerking geneem word hoe sterk die volkssoewereiniteit in die Zuid-Afrikaansche Republiek gefunksioneer het. Hier is geen skeiding tussen volk en staat (owerheid) nie. Die volk is die staat - daarom is dit bykans sinoniem om te praat van staatskerk of volkskerk. Kerk, volk en owerheid was organies verweef en die weefsel wat hierdie gemeenskap aanmekaar hou, is die verbond, soos dit sigbaar word in die doop. 
Die grondwet van 1858 handhaaf dus die organiese eenheid van kerk, volk en owerheid (Pont 1986:63). Wat duidelik word, is dat Artikel 20 van die grondwet nie net die Hervormde Kerk as staatskerk bepaal nie, maar dat dit ook die aard van die volk en die owerheid wesenlik bepaal. Die situasie wat deur die grondwet geskep is, was dat daar een Hervormde Kerk in die Zuid-Afriaansche Republiek was wat op die reformatoriese belydenisskrifte van die sestiende eeu gestaan het; een volk wat sy volkslewe volgens hierdie belydenis wou inrig en een owerheid wat bereid en begerig was om hierdie kerk en belydenis ten alle koste te beskerm. Hierdie situasie was soortgelyk aan die een wat in Nederland bestaan het met die totstandkoming van die gereformeerde kerkstaat in 1651 onder invloed van die calvinisties-teokratiese denke (Haitjema 1964: 10). Die ideaal is egter spoedig vernietig deur die afskeiding van die Gereformeerde Kerke onderleiding van ds D Postma en die afskeiding van die Nederduitsch Gereformeerde Kerk onder leiding van ds F L Cachet.

\subsection{Die posisie van nie-blankes}

Die tweede belangrike saak waaroor die Algemene Kerkvergadering verdere toeligting van die Volksraad wou hê, was oor die sending en die posisie van nie-blankes. Artikel 8 laat sendingwerk toe, maar onder voorwaarde dat daar 'geen bedrog en misleiding' sal plaasvind nie. Die kerk wou weet van watter bedrog en misleiding hier sprake is. Die antwoord wat op die vraag gegee is, was dat dit verwys na 'burgerlike misleiding en bedrog'. Hiermee word dus bedoel dat die sending nie vir politieke oogmerke misbruik mag word nie. Die Afrikaner se belewenis van die Londense Sendinggenootskap aan die Oosgrens het hierin 'n rol gespeel. Dit gaan dus juis daarom dat die owerheid sending toelaat en nie wil inmeng met die sendingwerk nie. Die sendingwerk moes evangelieverkondiging wees en nie deur politieke bymotiewe gekenmerk word nie.

Artikel 9 stel dat geen gelykstelling tussen gekleurdes en blanke ingezetenen toegelaat word nie. Die Volksraad verklaar dit as 'niet dezelvde godsdienstige voorregten in ons Kerkgebouw'. Dit is belangrik om daarop te let dat die Afrikaners in die Transvaal nooit werklik die swart stamme polities wou oorheers nie. Daarom was daar ook nooit sprake daarvan dat hulle as ingezetenen gereken sou word nie. Om 'n ingezetene te wees, het beteken dat iemand ' $n$ burger van die land is. 'Gelykstelling' het in effek beteken dat iemand burgerskap ontvang. Die verhouding tussen die blanke owerheid en die swart stamme is deur middel van ooreenkomste en kontrakte gereël en hulle het daarin die voorbeeld wat in die Kaapkolonie deur J A De Mist gestel is, gevolg (Murray 1962:112). De Mist het die politieke beginsel van pluralisme gevolg waarvolgens die soewereiniteit van die swart stamme erken is (die suos reges, suam rempublicum; suas leges, sua iura beginsel van Grotius). 
Dit is opvallend dat dit 'die wil van die volk is' dat daar geen gelykstelling in staat of kerk sal wees nie. Die onderskeid op grond van ras word dus deur die volkswil en grondwet in die kerk ingebring. Tog was hierdie sake so verweef, en ook vanselfsprekend, dat 'n mens ook moet sê dat die Algemene Kerkvergadering hierdie wetgewing sonder teëstem so aanvaar het. Vir die kerk was dit vanselfsprekend dat die kerk hom besig moet hou met die evangelieverkondiging aan die (Afrikaner-) volk. Die onderskeid word duidelik getref: evangelieverkondiging aan die nie-blankes is sending en funksioneer struktureel los van die evangelieverkondiging aan die eie volksgenote. Eersgenoemde is sending en laasgenoemde is pastoraat. Die evangelie word na buite en na binne verkondig.

As 'n mens die wortels vir hierdie rassebeleid in die Zuid-Afrikaansche Republiek wil gaan soek, dan lê dit waarskynlik in die volgende sake:

* sterk klem op die volk wat beteken het dat iemand wat vreemd was aan die Afrikaner, uitgesluit is van die regering;

* die groot teenstelling in hulle denke tussen heiden en Christen en die swart stamme was heidene;

* die voortdurende gewapende konflik tussen die swart stamme en Afrikaners het vyandskap veroorsaak;

* die verskil in opvoedingspeil en taal het dit onmoontlik gemaak om hulle in die regering op te neem en ook toe te laat om eredienste saam met die (blanke) gemeente by te woon;

* die negatiewe ervaring van die Oosgrens gemeenskap met die Engelse sendelinge en die Britse beleid ten opsigte van die nie-blankes. Dat gelykstelling tussen blank en nie-blank in beginsel nie uitgesluit was nie maar hoogs onwaarskynlik, blyk uit Artikel 11: 'Het wil geen gelykstelling van kleurlingen met blanke ingezetenen, dan na dat het de overtuiging gekregen heeft, dat de gelykstelling geen nadeel aan de Republiek kan te weeg brengen' (S A Argiefstukke Tvl, no 3:382).

\subsection{Kerk- en landsgrense val ooreen}

Die derde belangrike saak waaroor die Volksraad uitsluitsel moes gee, was aan Artikel 11 wat sê: 'Het volk behoudt ... onafhankelykheid en onschendbaarheid van kerk en staat ....' Die antwoord wat op die navraag gegee is, was dat dit beteken het dat die kerk 'niet gebonden onder enige Synode of Buitenlands opzicht' was nie. Die antwoord dui daarop dat die inlywing by die Kaapse Sinode steeds 'n kwessie was, 
veral aangesien Lydenburg se kerkraad onder die Kaapse Sinode wou ressorteer. Die volk het egter by dié beginsel gestaan dat die Zuid-Afrikaansche Republiek staatkundig onafhanklik is en daarom moet die kerk ook selfstandig wees. Die beginsel wat gegeld het, was dat landsgrense en kerkgrense ooreenval. Dieselfde beginsel het ook in die Kaapkolonie gegeld, soos blyk uit die bekende Loedolffsaak (vgl Van der Wait 1977:112). Dit was in daardie tyd, met die organiese verweefdheid wat tussen kerk, volk en owerheid bestaan het, vanselfsprekend dat daar in 'n soewereine land ook 'n selfstandige kerk moet bestaan. Die nie-inlywing van die kerk in die ZuidAfrikaansche Republiek by die Kaapse Sinode, is hiermee in die grondwet verskans en so ook die voortbestaan van die Nederduitsch Hervormde Kerk as selfstandige kerk in die Transvaal.

\section{SLOT:}

Die grondwet van die Zuid-Afrikaanse Republiek wat in 1858 uitgevaardig is, is in baie opsigte 'n unieke en interessante dokument. Dit weerspieël iets van die denke van die Transvaalse pioniers oor kerk, volk. en owerheid. Terwyl die res van die wêreld gedurende die negentiende eeu al meer in die rigting van groter skeiding tussen kerk en staat beweeg het en die teokrasie agtergelaat het, het die Transvaalse pioniers juis op ' $n$ teokratiese wyse gestalte gegee aan 'n nuwe gemeenskap in die Zuid-Afrikaanse Republiek. Hulle is hierin beïnvloed deur hulle pioniersomstandighede, die reformatoriese belydenisskrifte, die Calvinisme van die Nadere Reformasie, die Ou Testament wat as voorbeeld van die verbondsverhouding God-kerk-volk-owerheid gedien het asook die republikeinse denke van die Patriotte. Dit word ook duidelik dat die geskiedenis van die kerk in die Transvaal nie los van die staatkundige ontwikkeling van die Zuid-Afrikaansche Republiek verstaan kan word nie.

\section{Litaratuurverwysings}

Algemene Kerkvergadering, 1853-1869. Notulen van de Algemene Kerkvergaderingen der Nederduits Hervormde Kerk in de Z A R. Pretoria: S P Engelbrecht versameling, Kerkargief NHKA.

Beyers, C 1967. Die Kaapse Patriotte. Pretoria: Van Schaik.

De Visser, J T 1926. Kerk en Staat. Drie dele. Leiden: A W Sijthoff's Uitgeversmaatschappij.

Du Plessis, J S 1975. Die Suid-Afrikaanse Republiek, in Muller, C F J (red), 500 Jaar Suid-Afrikaanse Geskiedenis, Pretoria/Kaapstad: Academica.

Du Plessis, T A 1968. Stuart, Jacobus, in De Kock (red), SA Biografiese Woordeboek, Deel I. Kaapstad: Nasionale Raad vir Sosiale Navorsing. 
Engelbrecht, S P 1953. Geskiedenis van die Nederduitsch Hervormde Kerk van Afrika. Pretoria en Kaapstad: HAUM/J H de Bussy.

Haitjema, Th L 1964. De Nieuwere Geschiedenis van Neerlands Kerk der Hervorming. 's-Gravenhage: Boekencentrum.

Kleynhans, W A 1966. Volksregering in die Zuid-Afrikaansche Republiek: Die rol van Memories. Pretoria: Van Schaik.

Murray, A H 1962. The political philosophy of J A De Mist. Cape Town/Pretoria: HAUM.

Niewoudt, C F 1979. Die staatsreëlings van die Voortrekkers en die 'Boere, in Niewoudt, C F, Die politieke stelsels van Suid-Afrika. Pretoria: Academica.

Pont, A D 1986. Verbond en volkskerk. HTS 42, 28-76.

1991. Die verhouding 'kerk en volk' in die jare 1835-1900 in die Oorvaalse: 'n Terreinverkenning. HTS 47, 783-799.

S A Argiefstukke Transaal, no 3 1854-58. Notule van die Volksraad van die SuidAfrikaanse Republiek. Parow: Staatsdrukker.

Van der Watt, P B 1977. Die Nederduitse Gereformeerde Kerk 1834-1866. Pretoria: N G Kerkboekhandel.

Van Warmelo, N J 1881. Een herinnering aan ds Dirk van der Hoff. Herdruk in HTS 9, 170-176.

Wichmann, F A F 1941. Die Wordingsgeskiedenis van die Zuid-Afrikaansche Republiek 1838-1860. In Argiefjaarboek vir $S$ A Geskiedenis, 4. Kaapstad: Staatsdrukker.

Wypkema, A 1939. De invloed van Nederland op ontstaan en ontwikkeling van de Z A Republiek tot 1881. Pretoria: J H de Bussy. 